\title{
Welcome by Professor Roberto Bertolani
}

Dear All,

I wish also extend the greetings and best wishes for a successful meeting from Lorena Rebecchi and Roberto Guidetti, University of Modena and Reggio Emilia, co-organizers of the Symposium. I am very glad to meet you in Catania, some of you again, some others for the first time. Thank you to all participants. A particular welcome to Diane, the only person who shares with me participation to all ten Symposia.

I hope that this meeting may be an important occasion for an exchange of information, ideas, suggestions and debates among researchers who use tardigrades as a model, but are also interested in general and stimulating problems of animal biology.

Particular thanks to my collaborators, co-organizers and not, Lorena, Roberto, Tiziana and Deborah. Their collaboration has been fundamental for me and for this organization. A special thanks to my wife Silvana, for her patience and for her active collaboration in this event.

A special greeting to Binda \& Pilato, as cited in references, or better to Graziella and Giovanni, my good friends for a long time. I think that only our friendship has allowed this meeting, because I know that they do not like to appear. For this reason they should be pressed; but in the meantime they are very generous, as well as very competent. Their reserve is certainly one of the main reasons for their scarce participation at our previous meetings. But if Pilato does not go to the Symposium, the Symposium goes to Pilato. The request of a third Symposium in Italy was made in Tampa three years ago. The suggestion was South Italy, and possibly Sicily. Together with my collaborators, I offered my help to Binda and Pilato, and we are here!

Tardigradologists are not a formal organization or a society; events such as this meeting depend only on our good will and availability. Therefore, a special thank you to the previous meeting organizers: Livia Tonolli, Barbara Weglarska, Diane Nelson, Sandra McInnes, Hartmut Greven, Reinhardt Kristensen and Jim Garey.

Thank you to all of you. 